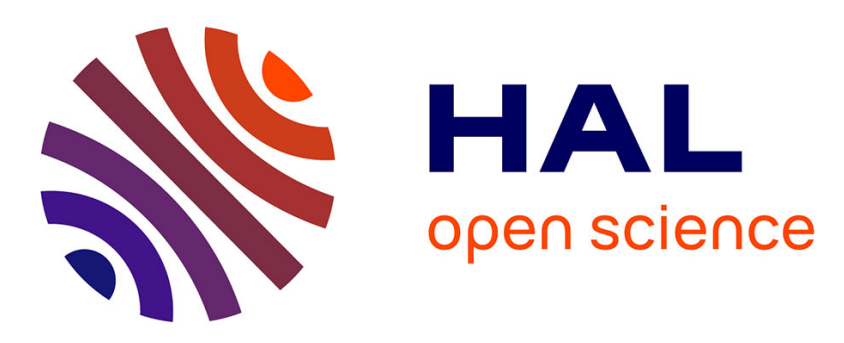

\title{
A Mechanical Spectroscopy Study of Neutron Irradiation and Thermal Ageing of Reactor Pressure Vessel Steels
}

K. van Ouytsel, R. de Batist, A. Fabry, F. Poortmans, R. Schaller

\section{- To cite this version:}

K. van Ouytsel, R. de Batist, A. Fabry, F. Poortmans, R. Schaller. A Mechanical Spectroscopy Study of Neutron Irradiation and Thermal Ageing of Reactor Pressure Vessel Steels. Journal de Physique IV Proceedings, 1996, 06 (C8), pp.C8-825-C8-828. 10.1051/jp4:19968177 . jpa-00254613

\section{HAL Id: jpa-00254613 https://hal.science/jpa-00254613}

Submitted on 1 Jan 1996

HAL is a multi-disciplinary open access archive for the deposit and dissemination of scientific research documents, whether they are published or not. The documents may come from teaching and research institutions in France or abroad, or from public or private research centers.
L'archive ouverte pluridisciplinaire HAL, est destinée au dépôt et à la diffusion de documents scientifiques de niveau recherche, publiés ou non, émanant des établissements d'enseignement et de recherche français ou étrangers, des laboratoires publics ou privés. 


\title{
A Mechanical Spectroscopy Study of Neutron Irradiation and Thermal Ageing of Reactor Pressure Vessel Steels
}

\author{
K. Van Ouytsel, R. De Batist*, A. Fabry, F. Poortmans** and R. Schaller*** \\ SCK-CEN, Boeretang 200, $2400 \mathrm{Mol}$, Belgium \\ * RUCA Antwerp, Belgium \\ ** VITO, 2400 Mol, Belgium \\ *** IGA-EPFL Lausanne, Switzerland
}

\begin{abstract}
Neutron irradiation and thermal ageing are known to cause embrittlement of pressure vessel steels, but the underlying microstructural processes are not well known. In order to acquire a better understanding of embrittlement, we investigate pressure vessel steels in unirradiated, thermally aged and neutron irradiated conditions, using an inverted torsion pendulum. Our studies have revealed a marked effect on the damping due to neutron irradiation, which, according to previous work, is related to interactions between dislocations and neutron induced defects. We also found that the magnitude of this effect depends on the steel type (JRQ, Doel, ...). Thermal ageing shows similar effects of hardening. A difference in the damping can also be observed between base and weld metal, giving an indication of the importance of the chemical composition. At a critical amplitude the behaviour of the damping with vibration amplitude changes considerably. This can be related to the onset of microplasticity. Our measurements have shown that the critical amplitude is higher for thermally aged steel than for unirradiated specimens, indicating an increase in microyield due to thermal ageing. However, such an effect has not yet been established beyond doubt for irradiated steel specimens. A comparison of these results with tensile test results will be presented.
\end{abstract}

\section{INTRODUCTION}

The design life of a nuclear power plant is generally about 40 years. In Belgium plant life management (PLIM) [1] allows for unspecified duration of the operation license, subject to a regulatory review every ten years. For a safe and cost-effective management of nuclear power plants, regulatory surveillance of the pressure vessel is of great importance. However, current surveillance programmes are based on an inadequate indexation of fracture toughness which leads to scatter and bias of regulatory embrittlement trend curves. There is a lack of data at operation exposures where poorly characterised damage mechanisms may play a role and a possibly hidden role of thermal ageing effects is not taken into consideration. For these reasons Belgium is developing an Enhanced Commercial Surveillance Strategy. This strategy is based on:

a) a more systematical evaluation of Charpy impact tests, additional tensile testing at lower temperatures and reconstitution of broken Charpy specimens.

b) reconstitution for additional Charpy specimens for precracking and slow bend testing to evaluate fracture toughness trends and bounds.

c) the development of plant-specific embrittlement trend curves, which is mainly based on investigating the microstructure of the vessel material, in support of damage modelling.

The microstructural investigation techniques, currently used at the Belgian Nuclear Research Institute in Mol to study embrittlement, are: Positron Annihilation Spectroscopy, Mössbauer Spectroscopy, Transmission Electron Microscopy and Mechanical Spectroscopy. The mechanical spectroscopy measurements, reported here, were conducted at $\sim 1.6 \mathrm{~Hz}$, using an inverted torsion pendulum at the Institut de Génie Atomique, Ecole Polytechnique Fédérale de Lausanne in Switzerland. The steels studied were all bcc steels: Doel I-II and IV base and weld (Belgian steels), JRQ (Japanese Reference Quality steel), 
EGF (German high Ni, Cr, Mo steel) and 73W (American Reference high $\mathrm{Cu}$ weld steel). The Doel and JRQ steels were studied in unirradiated, neutron irradiated and thermally aged condition. Measurements were performed as a function of temperature and of vibration amplitude.

\section{RESULTS and DISCUSSION}

\subsection{Measurements as a function of temperature}

In the investigated temperature range $(100-600 \mathrm{~K})$ the internal friction of the pressure vessel steels studied is low and constant. However, Munier [2] showed that, after low temperature ( $250 \mathrm{~K})$ plastic deformation, a damping spectrum can be observed at high strain amplitude. This spectrum was observed for all steels studied and can be described as follows (figure 1): At a frequency of $\sim 1.6 \mathrm{~Hz}$ screw dislocations obtain sufficient energy around $150 \mathrm{~K}$ to overcome potential barriers; at $\sim 315 \mathrm{~K}$ a maximum is reached for which the relaxation strength is proportional to the mobile dislocation density times the square of the average dislocation segment length; at $\sim 330 \mathrm{~K}$ interstitials are mobile and start to pin the dislocations, which results in a change in the behaviour of the frequency and influences the shape of the peak; at $\sim 420 \mathrm{~K}$ an indication of a second pinning process is sometimes present. Another peak was observed at $\sim 545 \mathrm{~K}$ for both JRQ and Doel steel. This peak could be of Snoek-Köster type.

Neutron irradiation introduces additional defects in a material. Figures 1 and 2 show the dislocation relaxation for JRQ (in wt\% C:0.18,Cr:0.14,Cu:0.14,Mn:1.42,Mo:0.51,Ni:0.84,P:0.017,S:0.004,Si:0.24) and Doel I-II (in wt\% C:0.15,Cr:0.58,Cu:0.145,Mn:0.96,Mo:0.32,Ni:0.79,P:0.01,S:0.01,Si:0.225) base metal in unirradiated, irradiated and thermally aged condition. Irradiated actually means irradiated with neutrons and thermally aged, since the irradiations take place at $\sim 290^{\circ} \mathrm{C}$ over a considerable period of time. The thermally aged specimens were placed in a non oxidising environment at $\sim 290^{\circ} \mathrm{C}$ for the same period.

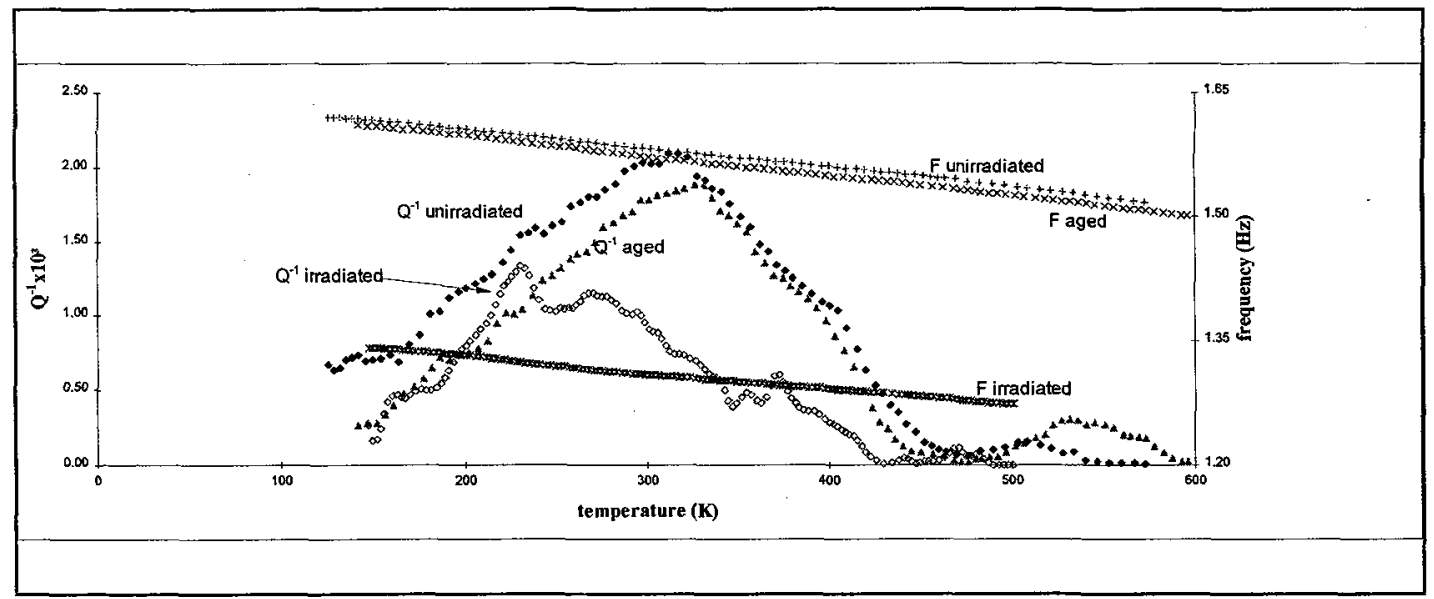

Figure 1: JRQ steel deformed $8 \times 1 \%$ at $\sim 250 \mathrm{~K}$ in unirradiated, irradiated $\left(1.07 \times 10^{19} \mathrm{n} / \mathrm{cm}^{2}\right.$ at $\left.\sim 290^{\circ} \mathrm{C}\right)$ and thermally aged $\left(\sim 3\right.$ years at $\left.\sim 290^{\circ} \mathrm{C}\right)$ condition

In JRQ and Doel I-II, neutron irradiation was found to decrease the internal friction maximum, i.e. the peak height, following the same amount of plastic deformation at $250 \mathrm{~K}$, is smaller in irradiated steels. A possible explanation [3] is that irradiation induced precipitates, composed of substitutional impurities, pin the dislocations and thus decrease the mobile dislocation density and the dislocation segment length.

Another effect of irradiation is a shift of the peak temperature to a lower value. Two models [3] have been suggested, but have not yet been established beyond doubt and will need to be verified for JRQ and Doel steels.

In general, JRQ steel exhibits a much lower peak than Doel steel. This would indicate that differences 
in chemical composition can be made visible by the experimental procedure. After irradiation (fluence of $1.07 \times 10^{19} \mathrm{n} / \mathrm{cm}^{2}$ ), the peak height for JRQ is lowered by a factor of almost two. For the Doel specimen a fluence almost four times as high $\left(3.97 \times 10^{19} \mathrm{n} / \mathrm{cm}^{2}\right)$ decreases the peak maximum with a factor a little higher than two. Quantitatively, the effect of neutron irradiation, clearly is different for JRQ and Doel steel.

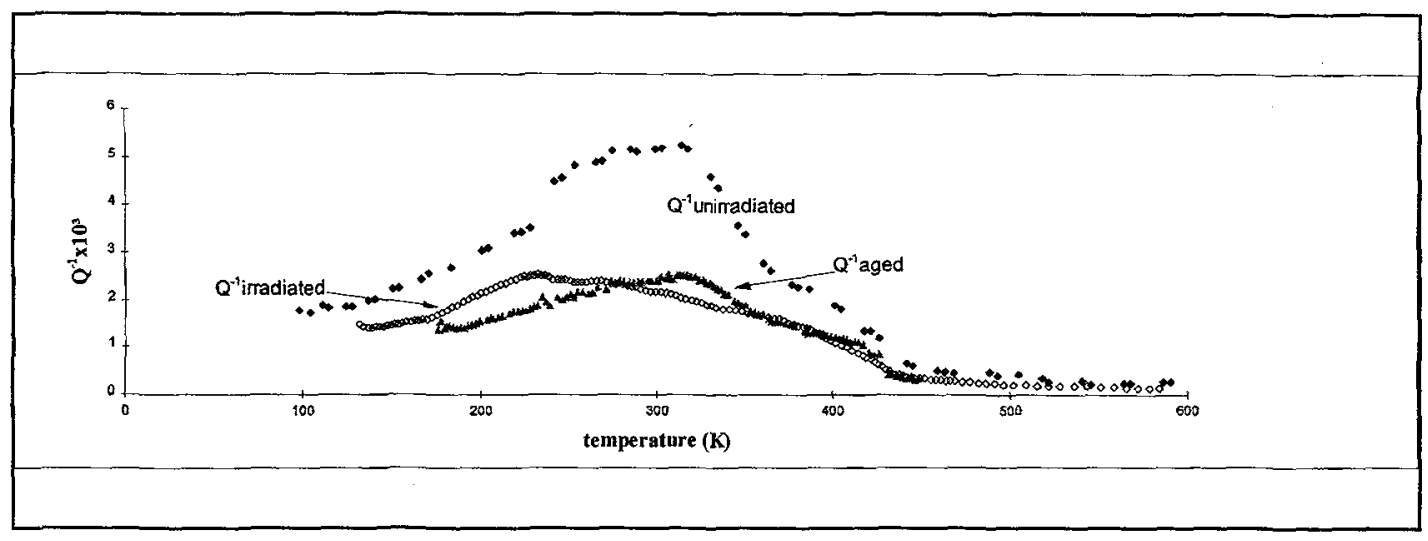

Figure 2: Doel I-II base metal, deformed $8 \times 1 \%$ at $\sim 250 \mathrm{~K}$, in unirradiated, irradiated $\left(3.97 \times 10^{19} \mathrm{n} / \mathrm{cm}^{2}\right.$ at $\left.\sim 290^{\circ} \mathrm{C}\right)$ and thermally aged $\left(\sim 63.000 \mathrm{~h}\right.$ at $\left.\sim 290^{\circ} \mathrm{C}\right)$ condition

Thermal ageing for $\sim$ three years $(\sim 26.000 \mathrm{~h})$ at $\sim 290^{\circ} \mathrm{C}$ does not seem to have a big effect for JRQ steel, but thermal ageing does influence the internal friction maximum for Doel material considerably. Ageing for 63.000 hours at $\sim 290^{\circ} \mathrm{C}$ lowers the internal friction maximum to the same degree as irradiation. No shift towards lower temperatures has been observed after thermal ageing for either material.

Because weld metal is usually more brittle than base metal, the internal friction of both base and weld Doel IV material was compared (base/weld in wt \% C:0.2/0.07, Cr:/0.14,Cu:0.055/0.046,Mn:1.43/1.57,Mo:0.53/0.48,Ni:0.75/0.78,P:0.008/0.017,S:0.008/0.005,Si:0.28/0.22). The weld metal revealed a dislocation relaxation with lower internal friction values than the base metal. This result is very promising in that it could well help to study the detrimental effects of particular elements introduced during welding. Not just differences between JRQ and Doel or base and weld metal have been observed. All the steels studied reveal quite remarkable differences in peak height. The internal friction for the $73 \mathrm{~W}$ (in wt\% C:0.1,Cr:0.25,Cu:0.31,Mn:1.56,Mo:0.58,Ni:0.6,P:0.005,S:0.005,Si:0.45) weld metal, for instance, was much lower than for the other steels, adding credibility to the above considerations.

\subsection{Measurements as a function of amplitude}

The internal friction as a function of amplitude exhibits a region at low amplitudes in which it is amplitude independent. At intermediate amplitudes the internal friction usually shows a linear dependence on the amplitude and then increases non linearly, levels off and exhibits a somewhat erratic behaviour at amplitudes well above the $0.2 \%$ yield. A critical amplitude can be determined and related to the onset of plasticity (Figure 3a). This critical amplitude can then be determined as a function of temperature. All steels studied in this way reveal low temperature hardening, characteristic for bcc metals. At low temperatures the critical amplitude is higher than at higher temperatures. The shape of this curve and the values for the critical amplitude are different for various materials and for steels in different conditions. Doel I-II steel in thermally aged condition shows an effect of hardening (higher critical amplitude) due to thermal ageing, when compared to the unirradiated material. Such an effect of hardening was not observed for JRQ steel after thermal ageing. These findings agree with results from Charpy impact and tensile tests. Figure $3 b$ shows the critical amplitude (multiplied with a normalisation factor, epscrit norm.) 
compared to tensile test data as a function of temperature. It also shows that the internal friction results correspond with a model for the yield strength [4], based on: a grain boundary contribution to yielding, a contribution from short range (Peierls) and one from long range (e.g. Cu precipitation) interactions. Moreover, because of the non destructive nature of internal friction, only one small specimen would be required to trace out the yield strength curve, whereas one specimen per data point is needed for tensile tests. Considering the limited amount of available reactor material, an internal friction based yield strength curve would be a valuable asset.

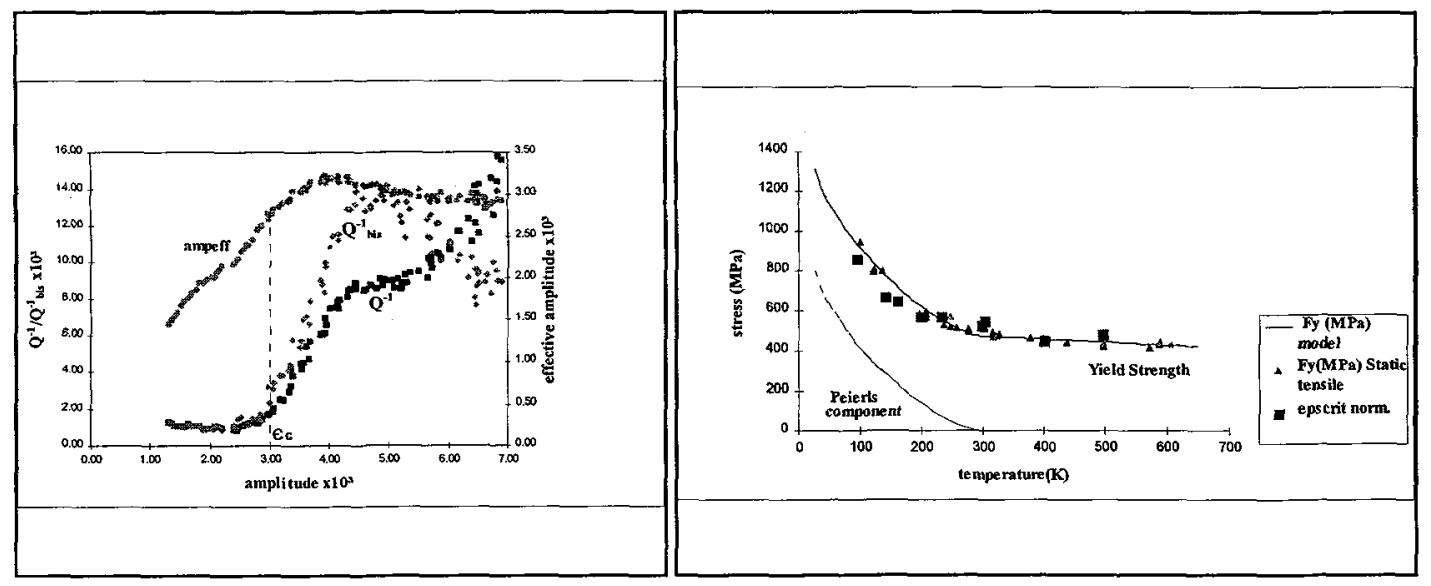

Figure 3a: Internal friction $Q^{-1}$ (amplitude) for JRQ at $\sim 500 \mathrm{~K}$ reveals a critical amplitude $\epsilon_{\mathrm{c}}$ which is determined from changes in the behaviour of $Q^{-1}, Q^{-1}$ bis and ampeff with amplitude. ampeff is the effective amplitude, corresponding with the second or third period in the free decay, where the calculation of $Q^{-1}$ is begun. $Q^{-1}$ bis is then determined from these first two or three periods in the free decay. Figure 3b: Yield strength as a function of temperature for unirradiated JRQ steel. The squares represent the critical amplitude, multiplied by a factor, while the yield stress, Fy, for tensile tests is shown in triangles. The internal friction data correspond with tensile data and with a three component model for the yield strength. The tensile tests were carried out at: GKSS (Germany), Saclay (France), JAERI (Japan), AEA (United Kingdom) and SCK·CEN(Belgium).

\section{CONCLUSION}

Internal friction is sensitive to differences in the microstructure of a variety of steels studied. Large effects of pinning of dislocations are visible and can give a better understanding of embrittlement due to neutron irradiation and/or thermal ageing. Amplitude dependent internal friction results can be related to tensile test results and correspond to a three component model for the yield strength. As a non destructive technique, requiring only one small sample to conduct a series of measurements, internal friction offers a promising means to contribute to a more plant-specific surveillance of reactor pressure vessel materials.

\section{References}

[1] Fabry A., Van de Velde J., Gerard R., 'Enhancing the surveillance of LWR ferritic steel components.' IAEA Specialists Meeting on 'Technology for Lifetime Management of Nuclear Power Plants', Tokyo, Japan 15-17 November 1994, (BLG 666, SCK·CEN, Mol, Belgium, 1994)

[2] Munier A., Maamouri M., Schaller R. and Mercier O., Journal of Nuclear Materials 202 (1993) 54-64. [3] Munier A., Frottement interieur et transition fragile-ductile dans les aciers ferritiques de cuves de reacteurs nucleaires (thèse No 951 EPFL, Lausanne, 1991) pp 125-126.

[4] Fabry A., van Walle E., J.Van de Velde and T.Petrova, 'RPV steel embrittlement:Damage Modeling and micromechanics in an engineering perspective', IAEA/OECD Specialists Meeting on Irradiation Embrittlement and Optimization of Annealing, Paris 20-23 September 1993, (BLG 649 SCK·CEN, Mol Belgium, 1993) pp. 17-25 